ZHANG Zhiqiang

\title{
Determining the optimal capital structure based on revised definitions of tax shield and bankruptcy cost
}

\author{
(C) Higher Education Press and Springer-Verlag 2009
}

\begin{abstract}
For half a century, no consensus has been reached on optimal capital structure after numerous intensive studies. This paper develops three alternative simple models to derive optimal capital structure. Because the optimal leverage ratio determined by the models is close to most survey data, some relevant puzzles, such as "financial conservatism", are easily explained. In addition, the new models can be extended to accommodate various decision situations, for instance, abnormal growth, bankrupt expectancy, debt guarantee, transaction cost, and personal income tax.
\end{abstract}

Keywords MM model, trade-off theory, tax shield, bankruptcy cost, ZZ leverage model

摘要 经过半个世纪的研究努力, 最优资本结构问题依然未得到解决。通过修正节 税收益和破产成本的概念, 并通过实物期权定价技术对这两者进行了重新计量, 进 而建立了确定最优资本结构的 $\mathrm{ZZ}$ 杜杆模型。将自变量的典型值代入模型得出的最 优债务比率与世界范围内的实际调查数据基本吻合, 从而一些长期难以解释的 “资 本结构之谜” , 如 “财务保守行为” 等, 可以得到解决。而且 $\mathrm{ZZ}$ 杜杆模型可以通 过简单调整, 方便地适应多种决策情况, 包括公司存在超常增长、破产预期、债务 担保、融资交易费用以及股权收益和债权收益的个人所得税差异等。

关键词 MM 模型, 权衡理论, 节税收益, 破产成本, $\mathrm{ZZ}$ 杜杆模型

Received October 13, 2008

ZHANG Zhiqiang $(\bowtie)$

School of Business, Renmin University of China, Beijing 100872, China

E-mail: zhqzh66@yahoo.com.cn 


\section{Introduction}

As the capital backing of investments and operations of firms include debt and equity, the capital structure is usually represented by the debt ratio, or the leverage ratio, as commonly referred to. The capital structure of a firm is, in practice, related to decisions made in financing the firm. The common way to choose a (optimal) debt ratio in financing is to trade-off the potential benefits (return) and costs (risk) related to the debt. This is in line with the trade-off theory (See Kraus and Litzenberger, 1973; Bradley et al., 1984; Kane et al., 1984; Brennan et al., 1984; and a review of the literature by Frank and Goyal, 2007).

It is widely believed that the main benefit from debt financing is corporate income tax savings, conventionally referred to as the tax shield, and the main cost is the resulting bankruptcy risk, conventionally referred to as bankruptcy cost or financial distress $\operatorname{cost}^{1}$. Surveys of financial decisions confirm these two factors frequently. For example, Graham and Harvey (2001), based on the responses from U.S. CFOs, reveals that firms stress financial flexibilities, credit ratings, earnings volatility and tax advantages in making debt decisions. Servaes and Tufano (2006) reveal that credit ratings, financial flexibilities and tax shields are the three most important factors determining the debt financing or capital structure in practice.

Since the MM II model of Modigliani and Miller (1963), it has been a convention in the study of optimal capital structure to value the tax shield on the basis of an infinite time horizon. However, a firm will surely go bankrupt in an infinite time horizon. Theoretically, each firm has a positive one-year bankruptcy probability. Although the one-year bankruptcy probability may be very small, the cumulative effect over decades or hundreds of years cannot be ignored ${ }^{2}$. Therefore, assuming a firm can have the tax shield forever obviously overvalues the tax shield and contradicts the conservative convention in financial decisions.

The measurement of bankruptcy cost could also be further discussed. Within the range of optimal capital structure, bankruptcy cost by the prevailing definition includes direct and indirect costs. Direct costs include items like legal, accounting, and other professional fees such as reorganization costs. and have been found to fall between $4 \%$ and $10 \%$ of a firm's value three years prior to

\footnotetext{
${ }^{1}$ The definition of bankruptcy cost in this paper is somehow different from the conventional or prevailing one. I will discuss the definition formally in Section 2 and 4.

${ }^{2}$ Statistically, the cumulative bankruptcy probability equals one minus the product of $n$ one-year survival probabilities. Take $1 \%$ as the bankruptcy probability in one year, the cumulative bankruptcy probability is over $50 \%$ in 69 years. This will rise to $63.4 \%$ over 100 years (the expected life of the company) and to $86.6 \%$ over 200 years (i.e. the cumulative survival probability is only $13.4 \%$ ).
} 
bankruptcy (see Altman, 1984). Indirect costs of bankruptcy include such factors as lost sales resulting from falling demand, declining margins from increased input costs, loss of key personnel and loss of management time and effort. Such costs are difficult to quantify and, consequently, most prior studies focus on the direct cost. ${ }^{3}$ However, it is generally believed that these indirect costs can be substantially larger than the more easily observed direct costs of bankruptcy. Therefore, the conventional measurement inevitably undervalues bankruptcy cost.

With the tax shield overvalued and bankruptcy cost undervalued, the "optimal" capital structure derived is relatively high, thus cannot explain the actual capital structures that occur in practice. For example, Graham $(2000,2001)$ found that conservative debt policy is a persistent and pervasive capital structure puzzle; a typical firm borrows considerably less than the theoretical amount predicted to be optimal. Miller (1977) argued that bankruptcy costs were not very important because they were small relative to the value gains from tax savings. He called the analysis of the tax benefits and distress costs a "horse and rabbit" stew, where the tax savings, the proverbial horse, outweigh the bankruptcy costs (the rabbit) by so much that we need not take distress costs into consideration.

Application of the method of contingent claim or option pricing makes a breakthrough in the studies of capital structure. Meanwhile, in order to explain existing capital structures, more effort has been shifted to factors such as information asymmetry, agency cost, personal income tax, product market competition, investment decisions, and macro economic conditions (See Frank and Goyal (2007) and their reference to the relevant literature). Factors like corporate income tax shield and bankruptcy cost are not taken into account.

The rest of this paper is organized as follows. The next section redefines the problem of the optimal capital structure and the relevant concepts - tax shield and bankruptcy cost. Section 3 discusses the valuation of the tax shield. Section 4 discusses the valuation of the bankruptcy cost. Section 5 derives the model of the optimal capital structure, i.e. the three models. Section 6 discusses some application extensions of the new model and Section 7 concludes this paper. The intensive derivations of the model of the optimal capital structure are shown in appendix.

\section{Definition}

A widely accepted reasoning of trade-off theory is to start from an unlevered

\footnotetext{
${ }^{3}$ There are also some scholars making efforts to estimate the indirect costs of bankruptcy, such as Haugen and Senbet (1988), Andrade and Kaplan (1998).
} 
situation in which a firm is $100 \%$ equity financed. Then as the debt capital in the capital structure increases, the tax shield will increase at a moderate rate while the bankruptcy cost will increase at a faster rate, starting from a point below the tax shield. There should be a point which maximizes the net benefit, or difference between the benefit and the cost of the debt financing. Therefore, the optimal capital structure can be defined as the point where the difference between the tax shield and the bankruptcy cost is maximized.

This paper focuses on the tax shield and the bankruptcy (distress cost) rather than other benefits and costs factors associated with debt financing. This is also in line with the tradition of theory. In finance, benefits and costs are normally measured on yearly basis. Total benefits and costs within consecutive years are measured by their summated values, i.e. the sum of the discounted benefits and costs respectively. For convenience, this paper refers to the total value of tax shields as the tax shield, and the total value of bankruptcy costs as the bankruptcy cost in the following parts.

In the normal case, when a firm goes bankrupt its value falls below the book value of its debt and its equity value falls to zero, with no chance of recovering to continuous operation. Thus on an infinite time horizon basis, the optimal capital structure of a firm is definitely $0 \%$ debt or $100 \%$ equity, rather than the $100 \%$ debt derived from the MM II model. Nevertheless, neither 100\% equity nor $100 \%$ debt is the correct answer for the optimal capital structure.

When a firm is considering financing, what it should care about is clearly the benefit and cost of its debt financing as determined by this round financing, rather than that in the last round financing or that in the next round financing or even financing in the distant future. This is just the process of the capital structure decision. Actually, no manager will base his/her (capital structure or other) decision on the infinite future even the tenure of the manager is ignored. As to bankruptcy, the simple and common case is that it can only occur at the maturity of the debt. Thus, it is natural to base the trade-off between tax shield and bankruptcy cost on the basis of one round of financing, i.e. the life of the debt. $^{4}$

Therefore, this paper redefine the problem of the optimal capital structure as: The debt ratio maximizing the difference between the tax shield and the bankruptcy cost before the maturity of the debt.

Since firms often have debts with various maturities in reality, to simplify the model we assume the maturity of debt here is the average maturity of all debts a firm has. In practice, a firm's debt is normally divided into long term debt and

\footnotetext{
${ }^{4}$ Some scholars study the capital structure decision with possible bankruptcy before the debt maturity, such as Ju et al. (2005). I will focus our attention on the usual situation, where the bankruptcy can only occur at the debt maturity.
} 
short term debt, or current debt as often called. A large part of current debt is commercial credit or other non-interest bearing debt, which cannot contribute to the tax shield. But this part of debt can contribute to the bankruptcy risk. Many studies on capital structure normally exclude this part of the debt and hence undervalue the bankruptcy cost. To avoid such a valuation bias, this paper define debt as the total debt of a firm, including both long term and short term debt. Consequently, the interest rate of the debt is the average interest rate of all debts of a firm, including long term and short term debt as well as non-interest bearing debt.

Currently, there is a large variety of definitions of bankruptcy cost. As mentioned earlier, the most widely accepted definition is that bankruptcy cost includes direct cost and indirect cost. Due to the difficulty in estimating bankruptcy cost, many prior studies only account for the direct cost. However, the indirect cost is also important. This is not only because the indirect cost is much larger than the direct cost, but also because it occurs far earlier and more frequently than the direct cost. Under most circumstances, for instance, the firm remains healthy as long as the maturity of its debt and the direct cost will not eventually occur. The direct cost is actually only the transaction cost in a bankruptcy deal. Thus this paper refers to it as the bankruptcy transaction cost and the indirect cost is the real bankruptcy cost.

How can we define and quantify such a cost? Conventional definitions and understanding are obviously too simple or irrelevant. The definition of bankruptcy cost should reflect the contingent characteristic of the concept. As debt financing increases the bankruptcy risk of a firm, it will consequently reduce the value of the firm. Therefore, this paper defines bankruptcy cost as the reduction of the value of the firm resulting from bankruptcy risk. Regarding the measurement of bankruptcy cost which is a contingent cost, there is no traditional method that can describe such a variable except the option pricing technique. Hence, this paper will further define bankruptcy cost as an option and value it by using the option pricing method in Section 4.

\section{Value of tax shield}

For the purpose of applying the option pricing model, this paper measures the capital structure as current value of total debt divided by current value of the firm, or value of total assets. This is different from the MM model, in which the capital structure is defined as the debt/equity ratio. Referring to the option pricing model of Black and Scholes (1973), this paper use $S$ and $X$ to denote current firm's value and current debt value respectively. So the capital structure is represented by the debt or leverage ratio $X / S$. 
Based on the convention in option or real option pricing, this paper assumes the firm value and the debt value are expected to grow at a continuous compound risk-free rate $r$ and calculate the present value in the model at the continuous compound rate $r$ (hence the effective annual interest rate in my model is somewhat larger than $r$ ). As the current market value of debt will not deviate from its book value significantly in normal situations, we do not account for the difference between the current market value and book value of the debt. Thus $X$ is also the book value of the debt and is the base to calculate the interest cost.

Additionally, in accordance with financial norms, the tax shield depends on the interest rate of the debt and the rate of corporate income tax and the maturity or life of the debt. This paper uses $b, f, T$ to denote these three variables respectively. As assumed in the last section, $b$ and $T$ represent the relevant average number. Besides the debt ratio $X / S$, time to maturity $T$, risk-free rate $r$, the bankruptcy cost also depends on the volatility of the firm's value. To remain consistent with the Black-Scholes option pricing model, this paper use $\sigma$ to denote the constant annual relative volatility of the firm's value.

All the denotations discussed above are listed as follows:

$S=$ current market value of the firm

$X=$ current debt value $=$ book value of the debt

$b=$ annual interest rate of the debt

$f=$ corporate income tax rate

$r=$ annual risk-free interest rate

$\sigma=$ annual relative volatility of the firm's value

$T=$ time to debt maturity (years)

Therefore, we base our estimation of tax shield on the average maturity $T$ and average interest rate $b$ of all debts with book or current value $X$ in a firm.

Please note that $S$ represents the current firm value and is different from that in the MM model, where it represents only the equity value. $X$ is different from the strike price $X$ in the option pricing model, which is the debt value at maturity. In other words, the $X$ here is equivalent to $X e^{-r T}$ in the standard option pricing model. In addition, the corporate income tax rate features progressive in some countries. In such a case, the above $f$ should be a marginal or effective tax rate. Therefore, the tax rate may be firm specified rather than country specified.

Now, perpetual tax shield of the debt is:

$$
\frac{X b f}{b}=X f
$$

$X f$ is equivalent to the $D T$ in MM model II, where $T$ is the corporate income tax rate.

Present value of the perpetual tax shield at the maturity of the debt is: 


$$
\frac{X b f}{b} e^{-r T}=X f e^{-r T}
$$

Therefore, value of the tax shield to the maturity of the debt is:

$$
\text { Tax shield }=X f-X f e^{-r T}=X f\left(1-e^{-r T}\right)
$$

For convenience in referring to the tax shield in equation (3), I will refer to it as ZZ tax shield. Obviously, ZZ tax shield $\left[X f\left(1-e^{-r T}\right)\right]$ is less than the tax shield in MM model II.

To illustrate this model, we could put realistic values of $X, f, r, T$ into equation (3). In practice, a short term debt lasts less than 1 year, a mid term debt lasts from 1 year to 5 years, and a long term debt normally lasts from 5 years to 30 years. As to the debt maturity structure, prior research documents that in a normal case, the longer of the debt maturity, the less of the amount ${ }^{5}$. Thus we simply assume a base case: firm value $S=100$; total debt $X=50$ with average maturity 5 years; Thus the debt ratio now is $50 \%$ (this is not necessarily the optimal debt ratio). To comply with the current normal situation, ${ }^{6}$ this paper assumes corporate income tax rate $f=33 \%$, risk-free rate $r=5 \%$. Based on equation (3), the ZZ tax shield is $50 \times 33 \%\left(1-e^{-5 \% \times 5}\right)=3.65$. However, based on MM model II and prevailing methods, the tax shield is $50 \times 33 \%=16.5$, which implies that the tax shield now is $350 \%$ (=16.5/3.65-1) overvalued.

Other taxes besides corporate income tax are not considered here. One reason is that these other taxes are relatively unimportant in the context of capital structure decisions. Moreover, if we could obtain the decision model based on corporate income tax, it should not be difficult to extend it to account for other taxes as well. Actually, most of other taxes may be easily deducted as a proportion of sales or value added or cost incurred in the relevant period. As to personal income taxes, this paper temporarily assume there is no significant difference between the tax rate on equity income and that on debt income. As a

\footnotetext{
${ }^{5}$ For example, Antoniou et al. (2006) reveal that the average long-term debt ratio, defined as debt that matures in more than one year to total debt, is 59\% in France, 53\% in Germany and 46\% in the UK. Similarly, according to the Global Vantage Data Base in 1991 presented by Rajan and Zingales (1995), compare to the total assets, percentage of average current debt, total debt and total equity of the G7 Countries (United States, Japan, Germany, France, Italy, United Kingdom, Canada) is $36 \%, 66 \%$ and $34 \%$ respectively. Therefore, the long term debt ratio is $(66 \%-36 \%) / 66 \%=46 \%$.

${ }^{6}$ According to the report of Randolph et al. (2005), effective marginal income tax rate is $41 \%$ for firms in the United States in 2003. It is $34.7 \%$ for other G7 countries, and $27.1 \%$ for non-G7 countries. Assuming weights of 25\%, 25\%, 50\% for United States, other G7 countries and non-G7 countries respectively, we can obtain a weighted average marginal corporate income tax rate about $33 \%$.
} 
result, personal tax as a whole is irrelevant for corporate financing or capital structure decisions. This paper will return to discuss the personal income tax before the end of this paper.

\section{Value of bankruptcy risk}

According to the definition in the last section, bankruptcy cost is the effect of bankruptcy risk in terms of value or cost. In corporate finance theory, a firm has two kinds of risk: one is operating risk, which shows as the fluctuations of earnings and value of the firm along with the change of the conditions within and outside the firm; the other is bankruptcy risk, which shows as the suspension of operation once the firm's value at the debt maturity falls below its debt book value. If a firm has no debt in its capital structure, it has only operating risk and hence has no bankruptcy risk and bankruptcy cost. In other words, a firm without debt will never need to worry about bankruptcy, no matter how low its value is.

As a convention in current practice, bankruptcy actually has double effects. On the one hand, it leads to the close of the firm (one punishment); on the other hand, it results in loss of the debtor and the creditor (another punishment). In other words, there is a double-punishment here. Conceptually, as the firm has already implemented all possible measures and the creditors have already suffered the loss, it is not necessary to additionally cease the operation of the zero-valued firm. To put it in another way, zero-valued firms' survival will not further hurt the creditors. As another practical convention, the creditor can be relieved from punishment by requiring the debtor to find a guarantor before offering the loan. In this case, bankruptcy also has double effect or punishment, with the difference that the potential punishment born by the creditor is now put on the guarantor.

Conceptually, despite the prevailing practice, double-punishment is neither fair nor necessary. To find a situation that can avoid such a double-punishment, consider a hypothesized "brother's guarantee". Suppose in a "brother's guarantee", one man offers a guarantee for his brother's debt. At the beginning, the debtor brother pays a fair guarantee fee to the guarantor brother and the guarantor brother promises that he will pay the unpaid debt at the maturity of the debt if the debtor brother does not have enough solvency, so that "privately" saves the "firm" from bankruptcy (but the debtor brother still needs to liquidate his assets to repay as much debt as he can).

Note that this debt guarantee is all the same as in a practical case, except that there is no problem of bankruptcy even if the value of the firm falls to zero. The debtor is relieved from worrying about bankruptcy at the maturity of his debt by paying a guarantee fee at the beginning. If the debtor's firm cannot fully repay the debt, there is only a single punishment born by the guarantor brother and 
neither the debtor nor the creditor will be punished. This paper assumes it is a fair deal between the two brothers from the beginning to the end, though that is not completely in line with practice. Because the guarantee contract can eliminate the bankruptcy risk for the debtor brother as well as the creditor, it conceptually implies that the fair guarantee fee he pays at the beginning equals the bankruptcy cost.

Since the bankruptcy cost equals the fair guarantee fee, the problem turns out to be how to calculate the fair guarantee fee, or the value of the guarantee. Prior real option studies reveal that the fair guarantee is a put option of the firm's value (Zhang, 1999). As Fig. 1 shows, the payoff of the portfolio including the risky debt and the guarantee is a level line, which represents a risk-free debt. The payoff of the guarantee is identical as that of a put option, with the exercise or strike price equal to the value of the debt at maturity, $X e^{r T}$.

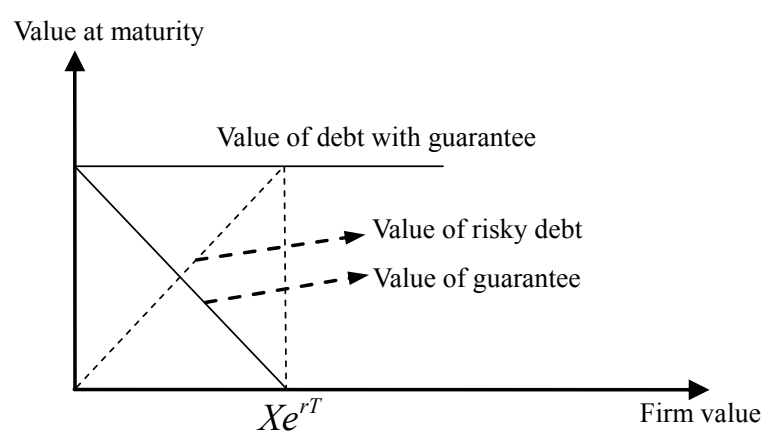

Fig. 1 Bankruptcy cost $=$ Value of debt guarantee $=$ Value of put option

Regarding the timing of the bankruptcy, as we discussed earlier, it is only possible at the maturity, $T$, of the debt. Thus the debt guarantee as a real option is exactly a European put option matured at $T$. Therefore, we can use the standard European put option pricing model directly to value the bankruptcy cost, which takes the form ${ }^{7}$ :

$$
\text { Put }=X e^{-r T} N(-d 2)-S N(-d 1)
$$

Where, $N(-d 2)$ and $N(-d 1)$ represent the cumulative probability under standard normal distribution when the variable equals $-d 2$ and $-d 1$ respectively, and

\footnotetext{
${ }^{7}$ Equation (4), (5) and (6) are the Black-Scholes option pricing model. See Black and Scholes (1973) and Merton (1973).
} 


$$
\begin{aligned}
& d 1=\frac{\ln (S / X)+\left(r+\sigma^{2} / 2\right) T}{\sigma \sqrt{T}} \\
& d 2=\frac{\ln (S / X)+\left(r-\sigma^{2} / 2\right) T}{\sigma \sqrt{T}}=\mathrm{d} 1-\sigma \sqrt{T}
\end{aligned}
$$

As the concept of $X$ in this paper is identical to $X e^{-r T}$ in above standard model, replace the $X e^{-r T}$ in above model by $X$ and we get the model of bankruptcy cost as follows:

$$
\text { Bankruptcy cost }=X N(-d 2)-S N(-d 1)
$$

Where,

$$
\begin{aligned}
& d 1=\frac{\ln (S / X)}{\sigma \sqrt{T}}+\frac{\sigma \sqrt{T}}{2} \\
& d 2=\frac{\ln (S / X)}{\sigma \sqrt{T}}-\frac{\sigma \sqrt{T}}{2}=\mathrm{d} 1-\sigma \sqrt{T}
\end{aligned}
$$

For convenience, this paper refers to equation (7) as ZZ bankruptcy cost. To continue with the realistic example in last section, in addition to $S=100, X=50$, $f=33 \%, r=5 \%, T=5$, assume further $\sigma=29 \%{ }^{8}$. Thus $S / X=2 ; \sigma \sqrt{T}=0.6485$. Based on the equation (7), (8) and (9), $d 1=1.3931, d 2=0.7447 ; N(-d 2)=$ $0.2282, N(-d 1)=0.0818$; ZZ bankruptcy cost $=3.23$; hence the bankruptcy cost is about $3.23 / 100=3.23 \%$ of the firm value ${ }^{9}$. The tax shield of this firm derived in the last section is 3.65 , which is a little more than the bankruptcy cost. Please note that this does not imply that the debt ratio (50\%) is too low, or the rational

${ }^{8} \mathrm{Ju}$ et al. (2005) calibrate the volatility of changes in the value of the unlevered firm to $38.02 \%$. But the volatility is often calibrated to $20 \%$ in prior studies, such as Leland (1973), Leland and Toft (1996), etc. Here the $29 \%$ volatility is simple the average of the $38.02 \%$ and the $20 \%$.

9 Prior studies document some empirical evidence of bankruptcy costs. For instance, Franks and Torous (1994) find the bankruptcy costs range as 50\% of firm value, Andrade and Kaplan (1998) conclude the bankruptcy costs range as 10-20\% of the high levered sample firms' value, Armstrong and Riddick (2001) find that the average decline in equity value over the 36 months prior to the filing date is $61 \%$. Despite of their large differences, these findings have little guidance for healthy firms to make decisions of financing or capital structure, because their conclusions are all based on the unhealthy firms, or firms close to bankruptcy. On the contrary, the bankruptcy cost we get here is for a typical and healthy firm. 
leverage ratio should be higher than $50 \%$. The optimal capital structure should be determined by the comparison of the marginal increase of tax shield and bankruptcy cost rather than the comparison of their total amounts. Anyway, since the bankruptcy cost is 3.23 and the tax shield is 3.65 , this "bankruptcy cost" is no longer a small rabbit comparing with the "tax shield horse".

\section{The optimal capital structure}

Combining equations (3) and (7), or subtracting ZZ bankruptcy cost from ZZ tax shield, we get the trade-off value or the net benefit of the debt financing:

Trade-off Value $=$ Net Benefit of Debt Financing

$=$ Tax shield - Bankruptcy cost

$$
=X f\left(1-e^{-r T}\right)-[X N(-d 2)-S N(-d 1)]
$$

As defined in Section 2, the value of $X$ maximizing the Trade-off Value or equation (10) is the magnitude of the debt to reach the optimal leverage ratio or capital structure. Mathematically, if we find the derivative of equation (10) with respect to $X$ and let the derivative equal 0 , we can obtain the condition or model of the optimal capital structure. The condition is shown as equation (11) with detailed derivation shown in Appendix A.

$$
N(-d 2)=f\left(1-e^{-r T}\right)
$$

Equation (9) gives the formula for calculate $d 2$. Let $L=X / S, S / X$ in equation (9) is just " $1 / L$ ". Note $\ln (1 / L)=-\ln (L)$,

$$
-d 2=-\frac{\ln (S / X)}{\sigma \sqrt{T}}+\frac{\sigma \sqrt{T}}{2}=\frac{\ln (L)}{\sigma \sqrt{T}}+\frac{\sigma \sqrt{T}}{2}
$$

Rewrite equation (11) as:

$$
\left.\mathrm{N}\left[\frac{\ln (L)}{\sigma \sqrt{T}}+\frac{\sigma \sqrt{T}}{2}\right]=f\left(1-e^{-r T}\right)\right]
$$

Equation (12) represents a precise relationship between the optimal leverage (or debt) ratio, $L$, and its influential variables. It is easy to find the optimal 
leverage or debt ratio $L$ based on equation (12) by the "goal seek" function in Microsoft Excel.

We use the "probit function" to "solve out" the $L$ in equation (12). In probability theory, the probit function is the inverse cumulative distribution function (CDF). So let $\operatorname{probit}(p)$ represent the inverse function of $N(p)$, i.e. $\operatorname{probit}(p)=N^{I}(p)$. Hence probit $[N(p)]=p$, i.e.,

$$
\begin{aligned}
& \frac{\ln (L)}{\sigma \sqrt{T}}+\frac{\sigma \sqrt{T}}{2}=\operatorname{probit}\left[f\left(1-e^{-r T}\right)\right] \\
& \begin{aligned}
\ln (L) & =\left\{\operatorname{probit}\left[f\left(1-e^{-r T}\right)\right]-\frac{\sigma \sqrt{T}}{2}\right\} \sigma \sqrt{T} \\
& =\operatorname{probit}\left(f-f e^{-r T}\right) \sigma \sqrt{T}-\sigma^{2} T / 2
\end{aligned} \\
& \left.L=e^{p r o b i t\left(f-f e^{-r T}\right.}\right) \sigma \sqrt{T}-\sigma^{2} T / 2
\end{aligned}
$$

Now we get the solution of equation (12) or another model of the optimal capital structure. There is a function "NORMSINV()" in Excel which can be used to calculate probit $(p)$. Moreover, we can also resort to inverse error function "erf ${ }^{1}$ " to express the optimal leverage ratio.

$$
\operatorname{probit}(p)=N^{-1}(p)=\sqrt{2} \operatorname{erf}^{-1}(2 p-1)
$$

Since $2\left(f-f e^{-r T}\right)-1=2 f-2 f e^{-r T}-1$, based on equation (15) and (16),

$$
\begin{aligned}
L & =e^{\sqrt{2} \operatorname{erf}^{-1}\left(2 f-2 \mathrm{fe}^{-\mathrm{TT}}-1\right) \sigma \sqrt{T}-\sigma^{2} T / 2} \\
& =e^{\operatorname{erf}^{-1}\left(2 \mathrm{f}-2 \mathrm{fe}^{-T}-1\right) \sigma \sqrt{2 T}-\sigma^{2} T / 2}
\end{aligned}
$$

To calculate the $\underline{\operatorname{erf}}^{-1}\left(2 f-2 f e^{-r t}-1\right)$, we can implement an "erfinv" function in MATLAB or "InverseErf" in Mathematica.

Therefore, we can derive the optimal debt ratio based on equation (12), (15) or (17). To keep consistency with the ZZ tax shield and ZZ bankruptcy cost, I would like to refer to equation (12), (15) and (17) as ZZ leverage model I, II and III respectively, or all the three models together as ZZ leverage model or ZZ model of the optimal capital structure. There is no simple expression for the 
cumulative probability of the standard normal distribution $N(p)$, its inverse function $\operatorname{probit}(p)$ or the inverse error function "erf ${ }^{1}$ ".

The following discussion adopts the above example, where $f=33 \%, r=5 \%$, $T=5, \sigma=29 \%$. Based on the ZZ leverage model I, II or III, by using the goal seek or NORMSINV() function in Excel or "erfinv" function in MATLAB or "InverseErf" in Mathematica, it is easy to find the optimal leverage ratio $L=$ $31.5686776659683 \%$, or $31.57 \%$ rounding to two decimals. This result is close to the facts documented by numerous empirical studies. As Ju et al. (2005) mentioned in their paper, the median firm in the Compustat database had a debt to total capital ratio of $22.62 \%$ in 2000 . Based on the worldwide capital structure survey by Jong et al. $(2007)^{10}$, the average worldwide debt ratio over the period 1997-2001 is $12.8 \%$. The leverage ratio is defined in the survey as book value of long-term debt over market value of total assets. According to the data of G7 Countries (Rajan and Zingales, 1995), the long term debt ratio is $46 \%$. Thus the $12.8 \%$ long-term debt ratio is equivalent to the total debt ratio of $27.83 \%(=12.8 \% / 46 \%)$, which is pretty close to our result of $31.57 \%$.

It is generally believed that "financial conservatism" has been created to bridge the big gap between the prevailing theoretical standard and reality (Graham, 2000, 2001). However, based on the ZZ leverage model, we find that practical leverage ratio is appropriate, and the theoretical standard is over optimistic.

Besides the dependent variable $L$, there are 4 influential variables in the $\mathrm{ZZ}$ leverage model. Based on the ZZ leverage model, it is easy to judge that the optimal capital structure or the optimal debt ratio will increase along with an increase in the tax rate and the risk-free rate, and will decrease along with an increase in the maturity of the debt and the volatility of the firm's value. These relationships are demonstrated in Table 1.

Table 1 The relationship between the influential variables and the optimal capital structure ("+" represents changing concurrently, and "-" represents changing reversely)

\begin{tabular}{lcc}
\hline Name of the variable & Denotation & Relation \\
\hline Corporate income tax rate & $f$ & + \\
Risk-free interest rate & $r$ & + \\
Maturity of the debt & $T$ & - \\
Volatility of the firm value & $\sigma$ & - \\
\hline
\end{tabular}

All the relationships in Table 1 could be easily explained except that between the maturity of the debt and the leverage ratio. A common reasoning is that relatively long term debt is close to equity in nature, so there should be a positive

\footnotetext{
${ }^{10}$ The average $12.8 \%$ is the unweighted simple average of the 40 sample countries (excludes two countries with extremely high and low leverage) calculated by the author.
} 
relationship between the maturity of the debt and the leverage ratio rather than the negative relationship in Table 1. Leland and Toft (1996), Stohs and Mauer (1996), among others, stand for this viewpoint. On the contrary, Dennis, Nandy and Sharpe (2000) showed that leverage is inversely related to debt maturity by their regressions. They argue that this happens because agency costs may be limited by reducing leverage and shortening debt maturity. Based on the reasoning of $\mathrm{ZZ}$ leverage model, uncertainty will increase with the increase of the debt maturity, which will therefore accelerate the increase of the bankruptcy cost. Thus, other things being equal, it is easier to borrow more short term debt than relatively long term debt.

Intuitively, the higher the interest rate of the debt, the bigger the tax shield and, thus, the optimal debt ratio should be higher. The ZZ leverage model does not take interest rate into account for two reasons. On the one hand, there is an opposite tendency, i.e. the higher the interest rate, the bigger the debt risk, thus the debt ratio should be lower rather than higher. This may work counter to the traditional viewpoint. On the other hand, the debt's interest rate is mainly determined by the market interest rate, the firm's risk and the maturity of the debt: the three factors that are already incorporated into the final model. Specifically speaking, risk-free rate $r$ represents the market interest rate; the volatility of the firm's value represents the firm's risk and debt maturity $T$ is also accounted in the model. Therefore, it is quite reasonable that the debt interest rate is not included in the model. On the contrary, if the debt interest rate is included, there will be a problem of variable redundancy or repetition. This explains a surprising finding in the survey of Servaes and Tufano (2006), which reveals that the interest rate or mispricing of debt is not important in practical capital structure decisions.

Similar deductions could be made on the probability of bankruptcy. A common viewpoint is that the higher the probability of bankruptcy, the larger the bankruptcy cost. Hence, some of the prior studies include the probability of bankruptcy in their models. Actually, the probability of bankruptcy is implied in the volatility of the firm's value and the debt maturity $T$. It is thus not necessary in most cases to further incorporate the probability of bankruptcy explicitly into the model. In addition, as a variable, the probability of bankruptcy is too difficult to estimate for a healthy firm, which inevitably hurts the validity of the model.

\section{Some application extensions}

In practice, there are various special situations in applying a model to find the optimal capital structure. This section discusses some application extensions of the basic $\mathrm{ZZ}$ leverage model. 


\subsection{Abnormal growth}

The ZZ leverage model focuses on the static situation, in which the firm's value keeps growing at the risk-free rate. Now we consider the dynamic feature of the capital structure, that is, how to take abnormal growth into account. Suppose that the firm's value will grow at a rate of $g+r$ or has an abnormal growth rate of $g$, and the firm plans to reach the optimal capital structure at the maturity of the debt. We have already accounted for growth rate $r$ in the ZZ leverage model. To account for the additional growth rate of $g$, we just need to rewrite $S$ in $\mathrm{ZZ}$ leverage model as $S e^{g T}$. Note that a debt ratio of $X /\left(S e^{g T}\right)$ at the debt maturity implies that the debt ratio now is $X /\left(S e^{g T} \times e^{-g T}\right)=X /\left(S e^{g T}\right) \times e^{g T}$.

Let us continue with the previous example. Suppose we use the same values for $f, r, \sigma, T$, except that the firm has an abnormal growth rate $g=10 \%$ (so that the total growth rate is $15 \%$ ). We have already known the optimal debt ratio of such a firm is $31.57 \%$ without (or after) the abnormal growth; thus the optimal debt ratio now (before the abnormal growth) should be: $31.57 \% \times e^{10 \% \times 5}=$ $52.05 \%$. Since the "abnormal" growth rate cannot last for long, an "abnormal" capital structure like the $52.05 \%$ derived here is not common. The above reasoning can be adjusted to account for any growth pattern of the firm's value before the debt matures. It can also be adjusted to satisfy any "optimal capital structure" requirement. If the above abnormal growth rate is expected to last only 2 years, or the firm plans to reach the optimal capital structure in the end of the year 2 for any reason, the optimal capital structure $(L)$ is now $31.57 \% \times e^{10 \% \times 2}=$ $38.56 \%$.

In practice, since the relationship between leverage and firm's value is not so clear, firms more often adjust their leverages infrequently and afterwards, because they usually consider the adjustment only at the refinancing point. The adjustment in advance as above is not common, thus the actual leverage may be indeed lower than the optimal standard, empirical research even finds an inverse relation between leverage and firm's profitability ${ }^{11}$. As explained by Strebulaev (2007), with infrequent adjustment, an increase in profitability "naturally" lowers leverage by increasing future profitability and thus the value of the firm. Similarly, a decrease in profitability "naturally" increases leverage which results in a negative relation between leverage and profitability.

\subsection{Expected bankruptcy}

The firm may be expected to go bankrupt at the maturity of the debt. In such a

${ }^{11}$ See Myers (1984, 1993). 
case, the value of the firm will be lower than the book value of the debt at the debt maturity, and the growth rate of the firm value will be negative during the life of the debt. Based on the ZZ leverage model, we can account for such expectancy by the same reasoning as that of the "abnormal growth rate" with a negative growth rate.

Suppose the firm value at the debt maturity is expected to be 40 from currently 100. As the debt book value is assumed to be 50 , this will cause the firm go bankrupt. The expected annual growth rate during the debt life is $\sqrt[5]{40 / 100}-1=$ $-16.74 \%$. We use the same values for $f, r, \sigma, T$, except that the firm has a total growth rate $-16.74 \%$ (so that the abnormal growth rate is $g=-21.74 \%$ ). As $L=$ $X /\left(S e^{g T}\right) \times e^{g T}$, the optimal capital structure $(L)$ is now $31.57 \% \times e^{-21.74 \% \times 5}=$ $10.64 \%$. Comparing with the optimal leverage ratio $31.57 \%$ of an "average" firm, this example shows that the bankruptcy expectancy can reduce the optimal leverage ratio sharply.

\subsection{Market value vs. book value}

Servaes and Tufano (2006) reveal that firms are concerned more with book value than market value measures. Only one fifth of companies specify debt to market value of equity as a primary measure. This may because of various factors: the market value of equity is volatile; managers find it often "incorrect"; and many firms are not publicly traded. Following the convention in studies of the optimal capital structure, the leverage in the ZZ leverage model is based on market values. The optimal debt ratio we obtain is also on the market value bases. However, it is not difficult to translate the optimal leverage ratio of market value into the optimal leverage ratio of book value. In a normal situation, market value will not deviate far from its book value as long as the firm keeps healthy, in which case we need not change the value of $X$. As to equity, when the firm is listed the total equity market value is the product of its share price and its number of shares outstanding. So it is easy to obtain the market/book ratio.

To illustrate the above inference, let us continue with the previous example, supposing the market/book ratio of its equity is 3 , and current book debt ratio is $60 \%$ or book equity ratio is $40 \%$. Then, the market/book ratio of the firm's value is $(3 \times 40 \%+1 \times 60 \%) /(1 \times 40 \%+1 \times 60 \%)=1.8$, and the book value of $S=$ market value of $S / 1.8$. As the optimal leverage ratio $L$ in market value is $31.57 \%$, the optimal leverage ratio $L$ in book value is $31.57 \% \times 1.8=56.83 \%$. Note that it is different from the original book debt ratio $60 \%$, which is an input to derive the result $56.83 \%$. This implies that there is an interaction between the original debt ratio and the derived optimal debt ratio. So we can use the "goal seek" function in Microsoft Excel based on the above simple relation to find the optimal leverage ratio $L$ in book value. As to the above case, the final result is $58.05 \%$. 
As to the firms that are not listed, we can first value its equity by various valuation methods, such as price-earning ratio, discounted cash flow, etc.

\subsection{Guaranteed debt}

Other things being equal, when a firm indeed has debt guaranteed by an outside or independent guarantor, as we have discussed, since the guarantee in practice cannot help the firm to avoid bankruptcy, the bankruptcy cost related to the guaranteed debt is as much as double (200\%) the fair guarantee fee. For such a case, based on equation (12), the ZZ leverage model should be rewritten as:

$$
2 \mathrm{~N}\left[\frac{\ln (L)}{\sigma \sqrt{T}}+\frac{\sigma \sqrt{T}}{2}\right]=f\left(1-e^{-r T}\right)
$$

It is easy to rewrite the ZZ leverage model based on equation (15) and (17), as they reflect the same reasoning and relations between the optimal leverage and the influential variables. Now, based on equation (18), we can find the optimal capital structure for a firm needing an outside guarantee to obtain debt capital.

Continue with the previous example. Assume the same values for $f, r, \sigma, T$, but the firm needs an outside guarantee and pays a fair guarantee fee up front. Calculated from equation (18), the optimal capital structure $(L)$ now is $25.34 \%$.

As small firms or startups are short of credit history, they usually need guarantees to obtain their debt financing. The above illustration in some way explains why small firms or startups normally have lower leverage ratios. Meanwhile, small firms or startups may grow faster. It makes sense to test a firm that has abnormal growth rate whilst needing an outside guarantee. Suppose all the previous data is valid for such a firm, i.e., it grows in the 2 years at an abnormal rate of $10 \%$ (in addition to a risk-free rate 5\%), and need a guarantee to obtain the debt capital. Its optimal capital structure $(L)$ now should be $25.34 \% \times e^{10 \% \times 2}=30.95 \%$. If we change to an even higher abnormal growth rate, the leverage ratio of the firm can consequently be even higher. This is inline with reality. For example, if the firm has vast potential in profitability and growth, such as Google, it will be easy to get debt capital and its leverage ratio can be high if it likes.

\subsection{Transaction costs}

Transaction costs are associated with debt financing. When the firm issues debt to the public, the costs are quite explicit - there are underwriting spreads and registration and legal fees. When the firm employs bank debt, there may be 
explicit fees in addition to the interest payment. However, when choosing between internal finance and issuing debt, transactions costs may well be important. Transaction costs can be handled as an additional guarantee fee, since they are both payments at the beginning. This method is more convenient than the convention in bond or equity valuation, in which the transaction costs are accounted for on per bond or per share bases. Suppose the expected transaction costs are totaled to $h$ times the guarantee fee. Using the same reasoning in accounting for the guaranteed debt, the ZZ leverage model should be rewritten as:

$$
(1+h) \mathrm{N}\left[\frac{\ln (L)}{\sigma \sqrt{T}}+\frac{\sigma \sqrt{T}}{2}\right]=f\left(1-e^{-r T}\right)
$$

Based on equation (19), we can find the optimal capital structure accounting for transaction costs.

Still use he previous example. Assume the same values for $f, r, \sigma, T$, but the firm needs to pay a transaction cost up front totaling $50 \%$ of the guarantee fee. Calculated from equation (19), the optimal capital structure $(L)$ is now $27.66 \%$. The optimal leverage ratio falls from the $31.57 \%$ in the base case to $27.66 \%$, which illustrates that the transaction costs make debt financing less attractive.

\subsection{Personal income tax}

In the context of capital structure decision or the trade-off between equity and debt, only the difference between the tax rate on debt or interest income and the tax rate on equity income is relevant to decisions. That is why prior surveys reveal that personal income tax is not an important factor in capital structure decision. However, ZZ leverage model can easily be extended to incorporate this factor whenever it is necessary.

Because personal tax rate on interest is generally higher than the tax rate on returns from common stock, there is a "personal tax penalty" associated with interest deductions. That is to say, investors demand a higher risk-adjusted pre-tax return for debt investments than that of equity investments.

Based on Miller's (1977) formula, we can account for the "personal tax penalty" by using $\left[1-\frac{(1-f)\left(1-f_{p e}\right)}{\left(1-f_{p d}\right)}\right]$ to replace $f$ in ZZ leverage model. 


$$
N\left[\frac{\ln (L)}{\sigma \sqrt{T}}+\frac{\sigma \sqrt{T}}{2}\right]=\left[1-\frac{(1-f)\left(1-f_{p e}\right)}{\left(1-f_{p d}\right)}\right]\left(1-e^{-r T}\right)
$$

Where $f$ is still the corporate income tax rate, $f_{p e}$ is the personal tax rate on equity income, and $f_{p d}$ is the personal tax rate on interest income.

Other things being equal, i.e. $f=33 \%, r=5 \%, T=3, \sigma=29 \%$, assume $f_{p e}=20 \%$, $f_{p d}=30 \%$. Thus $\left[1-\frac{(1-f)\left(1-f_{p e}\right)}{\left(1-f_{p d}\right)}\right]=23.43 \%$. The calculated optimal leverage ratio in Excel Goal seek is $L=28.21 \%$. The optimal leverage ratio falls from the $31.57 \%$ in the base case to $28.21 \%$, which illustrates that the personal tax penalty make debt financing less attractive. Of course, if there are special situations in which the personal tax rate on equity income is higher than the personal tax rate on interest income, i.e. there is a negative personal tax penalty, the debt financing will be more attractive with the personal tax taken into account. In our example, just assume $f_{p e}=30 \%, f_{p d}=20 \%$, then the optimal leverage ratio is $L=34.18 \%$.

Obviously, the basic ZZ leverage model is flexible to accommodate decisions of the optimal capital structure in various situations.

\section{Conclusion}

Based on the trade-off theory and the revised definitions of tax shield and bankruptcy cost, the article sheds light on the problem of the optimal capital structure. The optimal leverage ratio determined by the ZZ leverage model is significantly lower than the prevailing "theoretical standard", but very close to the actual capital structures documented by various survey reports. Most capital structure puzzles hence can be easily explained. This paper also extends the basic ZZ leverage model to account for various conditions possible in making practical decisions of the optimal capital structure, such as abnormal growth, bankrupt expectancy, guaranteed debt, transaction cost, personal tax, etc. These extensions further confirm the validity and flexibility of the ZZ model of the optimal capital structure.

\section{References}

Abramowitz M and Stegun I A (1965). Handbook of Mathematical Functions. New York: 
Dover Publications

Altman E (1984). A further empirical investigation of the bankruptcy cost question. Journal of Finance, 39(4): 1067-1089

Andrade G, Kaplan S N (1998). How costly is financial (not economic) distress? Evidence from highly leveraged transactions that became distressed. Journal of Finance, 53: 1443-1493

Antoniou A, Guney Y, Paudyal K (2006). The determinants of debt maturity structure: Evidence from France, Germany and the UK. European Financial Management, 12(2): 161-193

Black F and Scholes M (1973). The pricing of options and corporate liabilities. Journal of Political Economy, 81(3): 637-654

Bradley M, Jarrell G and Kim E H (1984). On the existence of an optimal capital structure: Theory and evidence. Journal of Finance, 39: 857-877

Brennan M J, Schwartz E S (1984). Optimal financial policy and firm valuation. Journal of Finance, 39: 593-607

Dennis S, Nandy D, Sharpe I G (2000). The determinants of contract terms in bank revolving credit agreements. Journal of Financial and Quantitative Analysis, 35: 87-110

Frank M Z and Goyal V K (2007). Trade-off and pecking order theories of debt. SSRN: http://papers.ssrn.com/sol3/papers.cfm?abstract_id $=670543$

Graham J (2000). How big are the tax benefits of debt? Journal of Finance, 55: 1901-1941

Graham J R and Harvey C (2001). The theory and practice of corporate finance: Evidence from the field. Journal of Financial Economics, 60: 187-243

Haugen R A and Senbet L W (1988). Bankruptcy and agency costs: Their significance to the theory of optimal capital structure. Journal of Financial and Quantitative Analysis, 23(1): $27-38$

Jong A, Kabir R, Nguyen T T (2007). Capital structure around the world: The roles of firm-and country-specific determinants. Working paper, http://ideas.repec.org/p/dgr/eureri/ 300011784.html

Ju N, Parrino R, Poteshman A M, Weisbach M S (2005). Horses and rabbits? Trade-off theory and optimal capital structure. Journal of Financial and Quantitative Analysis, 40(2): 259-282

Kane A, Marcus A J, McDonald R L (1984). How big is the tax advantage to debt? Journal of Finance, 39: 841-853

Kraus A, Litzenberger R H (1973). A state-preference model of optimal financial leverage. Journal of Finance, 28: 911-922

Leland H and Toft K (1996). Optimal capital structure, endogenous bankruptcy, and the term structure of credit spreads. Journal of Finance, 51: 987-1019

Merton R C (1973). Theory of rational option pricing. Bell Journal of Economics and Management Science, 4(1): 141-183

Miller M H (1977). Debt and taxes. Journal of Finance, 32: 261-275

Modigliani F and Miller M H (1958). The cost of capital, corporation finance, and the theory of investment. American Economic Review, 48(3): 261-297

Modigliani F and Miller M H (1963). Corporate income taxes and the cost of capital: A Correction. American Economic Review, 53(3): 433-443

Myers S (1984). The capital structure puzzle. Journal of Finance, 39: 575-592

Myers S (1993). Still searching for optimal capital structure. Journal of Applied Corporate Finance, (6): 4-14

Rajan R G, Zingales L (1995). What do we know about capital structure? Some evidence from international data. The Journal of Finance, 50(5): 1421-1460 
Randolph W, Williams R, Woodward T (2005). Corporate income tax rates: International comparisons. The Congressional Budget Office (CBO) Paper

Servaes H and Tufano P (2006). The theory and practice of corporate capital structure. Global Survey of Corporate Financial Policies \& Practices, Deutsche Bank

Strebulaev I A (2007). Do tests of capital structure theory mean what they say? The Journal of Finance, 62(4): 1747-1787

Stohs M H and Mauer D C (1996). The determinants of corporate debt maturity structure. Journal of Business, 69: 279-312

张志强 (Zhang Zhiqiang) (1999). 债务担保的价值 (Valuation of debt guarantee). 财经问题研 究, 187(6): 22-27

Appendix The derivation of the condition of the optimal capital structure

The condition of the optimal capital structure is that the trade-off value or the net benefit of the debt financing is maximized, or in another word, the derivative of equation (10) with respect to $\mathrm{X}$ should equal 0 :

$$
\begin{aligned}
& \left\{f X\left(1-e^{-r T}\right)-[X N(-d 2)-S N(-d 1)]\right\}^{\prime}=0 \\
& \left\{f X\left(1-e^{-r T}\right)-[X N(-d 2)-S N(-d 1)]\right\}^{\prime} \\
& =\left[f X\left(1-e^{-r T}\right)\right]^{\prime}-[X N(-d 2)-S N(-d 1)]^{\prime} \\
& =f\left(1-e^{-r T}\right)-[X N(-d 2)]^{\prime}+[S N(-d 1)]^{\prime}
\end{aligned}
$$

Since $N(-d 2)=1-N(d 2)$, and $N(-d 1)=1-N(d 1)$

$$
\begin{aligned}
{[X N(-d 2)]^{\prime} } & =\{X[1-N(d 2)]\}^{\prime} \\
& =[X-X N(d 2)]^{\prime} \\
& =(X)^{\prime}-[X N(d 2)]^{\prime} \\
& =1-\left\{(X)^{\prime} N(d 2)+X[N(d 2)]^{\prime}\right\} \\
& =1-N(d 2)-X[N(d 2)]^{\prime} \\
{[S N(-d 1)]^{\prime} } & =S[N(-d 1)]^{\prime} \\
& =S[1-N(d 1)]^{\prime} \\
& =-S[N(d 1)]^{\prime}
\end{aligned}
$$

Hence, 


$$
\begin{aligned}
& f\left(1-e^{-r T}\right)-[X N(-d 2)]^{\prime}+[S N(-d 1)]^{\prime} \\
& =f\left(1-e^{-r T}\right)-\left\{1-N(d 2)-X[N(d 2)]^{\prime}\right\}+\left\{-S[N(d 1)]^{\prime}\right\} \\
& =f\left(1-e^{-r T}\right)-1+N(d 2)+X[N(d 2)]^{\prime}-S[N(d 1)]^{\prime} \\
& =\left(f-f e^{-r T}-1\right)+N(d 2)+X[N(d 2)]^{\prime}-S[N(d 1)]^{\prime}
\end{aligned}
$$

Since $f(x)=\frac{1}{\sqrt{2 \pi}} e^{-\frac{x^{2}}{2}}$

$$
\begin{aligned}
& \begin{aligned}
& {[N(d 2)]^{\prime} }=\frac{1}{\sqrt{2 \pi}} e^{-\frac{(d 2)^{2}}{2}}(d 2)^{\prime} \\
&(d 2)^{\prime}=\left[\frac{\ln (S / X)}{\sigma \sqrt{T}}-\frac{\sigma \sqrt{T}}{2}\right]^{\prime} \\
&=\frac{\ln ^{\prime}(S / X)}{\sigma \sqrt{T}} \\
&=\frac{(X / S)(S / X)^{\prime}}{\sigma \sqrt{T}} \\
&=\frac{-(1 / X)}{\sigma \sqrt{T}} \\
&= \frac{-1}{X \sigma \sqrt{T}} \\
& {[N(d 1)]^{\prime}=\frac{1}{\sqrt{2 \pi}} e^{-\frac{(d 1)^{2}}{2}}(d 1)^{\prime} } \\
&(d 1)^{\prime}=\left[\frac{\ln (S / X)}{\sigma \sqrt{T}}+\frac{\sigma \sqrt{T}}{2}\right]^{\prime}=\frac{-1}{X \sigma \sqrt{T}}
\end{aligned}
\end{aligned}
$$

Therefore, $(d 1)^{\prime}=(d 2)^{\prime}=\frac{-1}{X \sigma \sqrt{T}}$ 


$$
\begin{aligned}
\left(f-f e^{-r T}-1\right)+N(d 2)+X[N(d 2)]^{\prime}-S[N(d 1)]^{\prime} & \left(f-f e^{-r T}-1\right)+N(d 2)+X\left[\frac{1}{\sqrt{2 \pi}} e^{-\frac{(d 2)^{2}}{2}} \frac{-1}{X \sigma \sqrt{T}}\right] \\
& -S\left[\frac{1}{\sqrt{2 \pi}} e^{-\frac{(d 1)^{2}}{2}} \frac{-1}{X \sigma \sqrt{T}}\right] \\
= & \left(f-f e^{-r T}-1\right)+N(d 2)-X\left[\frac{1}{\sqrt{2 \pi}} e^{-\frac{(d 2)^{2}}{2}} \frac{1}{X \sigma \sqrt{T}}\right] \\
& +S\left[\frac{1}{\sqrt{2 \pi}} e^{-\frac{(d 1)^{2}}{2}} \frac{1}{X \sigma \sqrt{T}}\right] \\
= & \left(f-f e^{-r T}-1\right)+N(d 2)-\frac{1}{\sigma \sqrt{2 \pi T}} e^{-\frac{(d 2)^{2}}{2}}+\frac{1}{\sigma \sqrt{2 \pi T}} e^{-\frac{(d 1)^{2}}{2}} \frac{S}{X}
\end{aligned}
$$

Thus, the condition of the optimal capital structure is:

$$
\left(f-f e^{-r T}-1\right)+N(d 2)-\frac{1}{\sigma \sqrt{2 \pi T}} e^{-\frac{(d 2)^{2}}{2}}+\frac{1}{\sigma \sqrt{2 \pi T}} e^{-\frac{(d 1)^{2}}{2}} \frac{S}{X}=0
$$

Based on

$$
\begin{aligned}
& d 1=\frac{\ln (S / X)}{\sigma \sqrt{T}}+\frac{\sigma \sqrt{T}}{2} \\
& d 2=\frac{\ln (S / X)}{\sigma \sqrt{T}}-\frac{\sigma \sqrt{T}}{2}=d 1-\sigma \sqrt{T}
\end{aligned}
$$

To simplify equation $\mathrm{A}(11)$, simplify the following part first: 


$$
-\frac{1}{\sigma \sqrt{2 \pi T}} e^{-\frac{(d 2)^{2}}{2}}+\frac{1}{\sigma \sqrt{2 \pi T}} e^{-\frac{(d 1)^{2}}{2}} \frac{S}{X}
$$

In the above part,

$$
\begin{aligned}
(d 1)^{2} & =\left[\frac{\ln (S / X)}{\sigma \sqrt{T}}+\frac{\sigma \sqrt{T}}{2}\right]^{2} \\
& =\frac{\ln ^{2}(S / X)}{\sigma^{2} T}+\ln (\mathrm{S} / \mathrm{X})+\frac{\sigma^{2} T}{4} \\
e^{-\frac{(d 1)^{2}}{2}} & =e^{-\frac{\ln ^{2}(S / X)}{2 \sigma^{2} T}} e^{-\frac{\ln (S / X)}{2}} e^{-\frac{\sigma^{2} T}{8}}
\end{aligned}
$$

Similarly,

$$
\begin{aligned}
(d 2)^{2} & =\left[\frac{\ln (S / X)}{\sigma \sqrt{T}}-\frac{\sigma \sqrt{T}}{2}\right]^{2} \\
& =\frac{\ln ^{2}(S / X)}{\sigma^{2} T}-\ln (\mathrm{S} / \mathrm{X})+\frac{\sigma^{2} T}{4} \\
e^{-\frac{(d 2)^{2}}{2}} & =e^{-\frac{\ln ^{2}(S / X)}{2 \sigma^{2} T}} e^{\frac{\ln (S / X)}{2}} e^{-\frac{\sigma^{2} T}{8}}
\end{aligned}
$$

Therefore,

$$
\begin{aligned}
& -\frac{1}{\sigma \sqrt{2 \pi T}} e^{-\frac{(d 2)^{2}}{2}}+\frac{1}{\sigma \sqrt{2 \pi T}} e^{-\frac{(d 1)^{2}}{2}} \frac{S}{X} \\
& =\frac{1}{\sigma \sqrt{2 \pi T}}\left[\frac{S}{X} e^{-\frac{(d 1)^{2}}{2}}-e^{-\frac{(d 2)^{2}}{2}}\right] \\
& =\frac{1}{\sigma \sqrt{2 \pi T}}\left[\frac{S}{X} e^{-\frac{\ln ^{2}(S / X)}{2 \sigma^{2} T}} e^{-\frac{\ln (S / X)}{2}} e^{-\frac{\sigma^{2} T}{8}}-e^{-\frac{\ln ^{2}(S / X)}{2 \sigma^{2} T}} e^{\frac{\ln (S / X)}{2}} e^{-\frac{\sigma^{2} T}{8}}\right]
\end{aligned}
$$




$$
\begin{aligned}
& =\frac{1}{\sigma \sqrt{2 \pi T}} e^{-\frac{\ln ^{2}(S / X)}{2 \sigma^{2} T}} e^{-\frac{\sigma^{2} T}{8}\left[\frac{S}{X} e^{-\frac{\ln (S / X)}{2}}-e^{\frac{\ln (S / X)}{2}}\right]} \\
& =\frac{1}{\sigma \sqrt{2 \pi T}} e^{-\frac{\ln ^{2}(S / X)}{2 \sigma^{2} T}} e^{-\frac{\sigma^{2} T}{8}\left[\frac{S}{X}\left(\frac{S}{X}\right)^{-\frac{1}{2}}-\left(\frac{S}{X}\right)^{\frac{1}{2}}\right]} \\
& =\frac{1}{\sigma \sqrt{2 \pi T}} e^{-\frac{\ln ^{2}(S / X)}{2 \sigma^{2} T}} e^{-\frac{\sigma^{2} T}{8}} * 0 \\
& =0
\end{aligned}
$$

Thus, the condition of optimal debt ratio is simplified as:

$$
\begin{aligned}
& \left(f-f e^{-r T}-1\right)+N(d 2)=0 \\
& N(d 2)=1-f+f e^{-r T} \\
& N(-d 2)=f\left(1-e^{-r T}\right)
\end{aligned}
$$

